\title{
Construction on Government Emergency Management System for Urban Emergencies in Big Data Era
}

\author{
Yongchang $\operatorname{Ren}^{1,}$, , Zhe $\mathrm{Li}^{2, \text { b }}$ \\ ${ }^{1}$ College of Information Science and Technology, Bohai University, Jinzhou, 121013, China \\ ${ }^{2}$ College of International Exchange, Bohai University, Jinzhou, 121013, China \\ arycryc@sina.com, b503412508@qq.com
}

Keywords: big data era; urban emergencies; government emergency management; system; construction

\begin{abstract}
The emergency management system is an organic whole with certain functions in the emergency management process, which is composed of several elements of emergency management, according to a certain structural form. It is also an organic combination of professional technology, management methods, behavioral norms, implementing agencies, and can complete various programs and measures to deal with emergencies. In view of the problems existing in the construction of government emergency management system for urban emergencies, following the basic principles of urban emergency management system construction in urban emergencies, the government emergency management system for urban emergencies in the era of big data was constructed. Specifically, it includes the organizational system, the plan system, the guarantee system, and the big data support system. The research results are used to guide specific emergency management practice.
\end{abstract}

\section{Introduction}

Big data refers to the collection of a large amount of data information, which cannot be completed by traditional data analysis and processing software, and has the characteristics of large amount of data and various types. Big data-based systems have a wide range of applications, and big data applications to government authorities can effectively improve the relationship between government and citizens. Big data technology can be fully integrated with cloud computing. By analyzing and interpreting a large amount of data information, it can obtain data information with deep meaning, which can provide reference for prevention and decision-making of various emergencies, and promote emergency response capability. Effectively improve. The application of big data in emergency management includes data storage, data collection, cloud computing and other parts. Through the improvement of emergency management level of big data, emergency management has stronger predictability, so that management can be effective respond and prevent emergencies.

The application of big data in emergency management is mainly to cooperate with the various processes of emergency management, so that the level and quality of emergency management can be effectively improved, and emergency management can meet the basic needs of government departments. Pre-preparation is mainly to configure the basic facilities and systems of big data, so that big data can provide reference for emergency management. In response, the main task is to combine management activities with big data applications to control emergency events and handle incidents. Afterwards, the implementation of decision-making can be smoothly carried out, reduce the hidden dangers of various types of security risks and emergencies, scientifically organize the recovery afterwards, and promote the orderly and rationality of the recovery afterwards.

The era of big data makes all kinds of basic data a usable resource, and the use of big data can realize social management innovation. Compared with the changes that have been realized in the commercial field, big data will also change and promote the development of China's emergency management system. Applying big data technology and thinking to emergency management, and 
realizing emergency management system innovation is an effective way to develop emergency management in China under the background of big data.

\section{Existing Problems on Construction of Government Emergency Management System for Urban Emergencies}

The construction of China's emergency management system has been perfected. However, as the difficulty of dealing with emergencies increases, the existing emergency management system also has the following problems:

(1) Strong post-serious incidents, light prevention. Emergency management should adhere to the principle of combining prevention, prevention and emergency, and fully prepare for the ideological preparation, preparation, organization and material preparation for responding to emergencies. The focus of China's current emergency response is still at the level of emergency response and rescue, lack of preventive work beforehand, and lack of process management for emergencies.

(2) Strong qualitative, light quantitate. Quantitate analysis and qualitative analysis are two analytical methods used in the understanding of affairs. They are related to each other and complement each other. At present, most of the research on emergency management focuses on related concepts and system analysis, while in emergency response, it pays too much attention to rights division and responsibility identification. There are few scientific decision-making methods based on data analysis.

(3) Strong construction, light linkage. Strengthen coordination and coordination, actively promote resource integration and information sharing, establish an emergency management contact working mechanism, and study outstanding problems in emergency management. However, under the traditional bureaucratic system, various departments are in a state of fragmentation, poor communication of information and excessive division of labor, which has led to frequent incidents in emergencies.

(4) Strong government, light society. The government plays an absolute and important role, emphasizing top-down national power and government mobilization, and lack of participation from civil forces. The response to emergencies relies too much on government power. Public participation only stays on the surface, defects are also obvious, and the contradiction between the complex and volatile events of the society and the limited processing capacity of the government is prominent.

\section{Basic Principles on Construction of Government Emergency Management System for Urban Emergencies}

The 13th Five-Year Plan for the establishment of a national emergency response system has clarified the basic principles for the construction of a government emergency management system for urban emergencies:

(1) Adhere to the source of governance and move forward. Innovate emergency management systems and methods, strengthen the combination of prevention and emergency, and combine normal and abnormal states; strengthen risk identification and assessment, maximize risk control and eliminate hidden dangers, and promote emergency management from emergency disposal to focus on risk management throughout the process.

(2) Adhere to the bottom line thought and be prepared. Focusing on the most severe and complicated situation, in-depth study of the dynamic evolution law of the occurrence and development of emergencies, and taking the problem as the guide, put forward the need for emergency prevention and emergency capacity building, and make targeted emergency preparations, firmly grasp the initiative. right.

(3) Adhere to resource integration and highlight key points. On the basis of making full use of the resources of emergency rescue and support capabilities of the government and society, we will sort out departmental and local needs, rationally plan the construction content that needs to be further supplemented, improved and strengthened, focus on improving information and resource 
sharing mechanisms, and improve core emergency rescue capabilities. , social synergy and basic infrastructure.

(4) Adhere to the scientific response and the rule of law. Respect the nature, respect the law, proceed from the reality, innovate scientific and technological means and methods, improve the scientific level of emergency management; improve the laws and regulations, strengthen standards and norms, and improve the decision-making mechanism according to law.

(5) Adhere to government leadership and social synergy. Improve government governance, pay more attention to the role of market mechanisms, fully mobilize the enthusiasm, initiative and creativity of the masses, strengthen social participation; improve the linkage mechanism of all parties, strengthen regional coordination, urban-rural coordination, industry synergy, and military-field synergy.

(6) Adhere to the global vision and win-win cooperation. Serving the "One Belt, One Road" as a leading new all-round opening pattern, improving the protection of our overseas citizens and institutions; strengthening international management and cooperation in emergency management, actively taking on international responsibilities and obligations, and constructively participating in international emergency affairs.

\section{Organization System on Government Emergency Management for Urban Emergencies}

Establishing a scientific and standardized urban emergency management organization system is the basic guarantee for responding to sudden public safety incidents in cities. It is conducive to preventing the occurrence of sudden public safety incidents, facilitating rapid response and handling of incidents, and helping to reduce disaster losses. The city needs to follow the principles of "unification of objectives, division of labor, unified command, equal rights and responsibilities, implementation and supervision of the departments" according to its own characteristics, basic conditions and types of events, etc., adapting to local conditions, adapting to the circumstances, and adapting to the circumstances. Establish the permanent emergency response agency and special command department, as well as other professional institutions, and build an emergency management organization system with clear functions and close coordination.

The Urban Emergency Management Committee is the core department for emergency management of emergencies. It is directly managed by government departments to meet the needs of rapid response to emergency management. The Municipal Emergency Management Committee has a government emergency management office as the central nerve of the emergency management committee, responsible for the specific emergency management work; the emergency special command organization, under the unified leadership and command of the emergency management committee, is responsible for the event in a rapid and orderly manner. Rescue assistance and handling after-care work; emergency professional consulting agencies provide professional prediction and consultation for sudden events such as natural disasters, public health events, and social security incidents; build a three-dimensional, all-dimensional, multi-level government burst, the incident response coordination organization can form a horizontal communication mechanism between the various emergency departments of the government; the emergency monitoring and evaluation institution uses scientific means to synchronously supervise and evaluate the people and events in the emergency management process, which is conducive to improving the disposal incident. Ability to accumulate relevant knowledge and experience in emergency management.

\section{Plan System on Government Emergency Management for Urban Emergencies}

The emergency plan is the direct basis for the emergency response, and the quality of the emergency plan determines the quality of the emergency response. The "National Emergency Response Plan for Public Emergencies" stipulates the composition of the national emergency response plan system: the overall plan is the general outline of the national emergency plan system, and is the normative document of the State Council to deal with special major public emergencies; 
the special plan is the State Council and the relevant departments, the emergency plan for responding to certain types or types of public emergencies; the departmental plan is formulated by the relevant departments of the State Council in response to public emergencies according to the overall emergency plan, special emergency plan and departmental duties. The local emergency plan includes the general emergency plan for public emergencies of the provincial people's government, special emergency plans, departmental emergency plans, the people's governments at the municipal and county levels, and the emergency plans for public emergencies organized by the grassroots political organizations; emergency plans formulated by enterprises and institutions in accordance with relevant laws and regulations.

The emergency plan system is a comprehensive manifestation of the emergency system, mechanism and legal system. Its operation depends on the coordination and support of the emergency system, mechanism and legal system. The relationship between the emergency plan system and the emergency system is that the normal emergency organization can have more energy, invest in emergency capacity building, which is conducive to the accumulation of experience, and can improve emergency management through continuous learning, and can play an emergency more than the emergency organization. The effectiveness of the plan system; the emergency plan system and the emergency mechanism are mainly related to the process, the steps are clear, the resources are clear, the upstream and downstream information is smooth, and the decision conditions are operational. The emergency mechanism can be used to make the emergency plan system effective; The main connection between the system and the emergency legal system is that the emergency legal system provides legal authorization for actions in the emergency plan. If the legislation lags behind, the emergency plan system will inevitably carry out emergency actions beyond the scope of legal authorization, which may lead to doubts about the legality of emergency actions, and thus affect the application effect of the emergency plan system.

\section{Security System on Government Emergency Management for Urban Emergencies}

Emergency management guarantee refers to the protection behavior of specific objects used by the government in the handling of emergency and accidental events. The emergency management and protection system is the most basic guarantee for carrying out emergency work and is the prerequisite for the government to perform its administrative duties. Emergency protection has four essential characteristics: first, the suddenness of behavior, mainly for the emergency protection of emergency implementation. Second, the speciality of strength, the support force for the establishment of emergency protection for a certain emergency. Third, the specificity of time and space, under certain time and space conditions, the protection of emergency or major rescue operations. Fourth, the particularity of the object is mainly for the emergency protection of emergency groups and specific groups of people who need assistance due to emergencies.

The main measures for the construction of the security system include: first, the establishment of an emergency security management system. The overall requirement is that the relationship should be rationalized, the structure should be reasonable, the command should be sensitive, the decision-making should be timely, the coordination should be effective, and the guarantee should be strong. Establish an emergency support command organization, coordinate the forces of all parties, implement unified command, maximize the enthusiasm, initiative and creativity of command managers at all levels, seize the opportunity of protection, and complete the support tasks. Second, improve the emergency support operation mechanism, focusing on strengthening the early warning mechanism, information disclosure mechanism, accountability and error correction mechanism, power mobilization mechanism, and international cooperation and coordination mechanism. The third is to promote the construction of emergency support teams to achieve quality, structural optimization and strength matching. Strengthen the training of new technologies and new equipment, so that security personnel can use advanced technical means to participate in emergency support activities; fourth, accelerate the construction of emergency support legal system, formulate unified emergency emergency protection regulations, and standardize emergency protection behaviors by legislation. Identify the institutions, functions, authorities, operating methods and 
sources of funding for emergency protection to ensure that emergency protection is carried out in accordance with the law.

\section{Big Data Support System on Government Emergency Management for Urban Emergencies}

Big data is changing the world today, and data collection and analysis is an important means of improving emergency management functions. The application of big data in emergency management is divided into two parts: big data technology and big data thinking. Big data technologies include both old technologies such as data warehousing, data marts, and data visualization, as well as new technologies such as cloud storage and cloud computing. The big data thinking is to find problems from the massive data, to think about the problem with the whole sample thinking, and to form a fuzzy, relevant and integrated way of thinking. The combination of big data technology and thinking has shaped the application of big data and has had a huge impact on many public management areas, including emergency management.

The application of big data consists of four characteristics: rapid collection, analysis, decision-making and response mechanisms; high credibility in analysis and conclusions; more predictive in terms of individual or group behavioral predictions and higher accuracy; value data and make the most of it, it is best to be able to use the data multiple times. According to the chronological order of emergencies, the entire emergency management can be roughly divided into three stages: pre-preparation, in response, and post-event: in the pre-preparation stage, corresponding management and facility preparation for big data applications are required; the application of big data can greatly facilitate the emergency response of the government, third-party organizations or individuals; the application of big data in emergency management is mainly in the rescue, recovery and reconstruction.

\section{Acknowledgement}

This work is supported by 2018 annual economic and social development project in Liaoning province (2018lslktyb-001): Government emergency management innovation of Liaoning urban emergencies in big data era.

\section{References}

[1] X. T. Wu, D. Y. Ji, A. Chen, "Opportunities and Challenges of the Reform of China's Emergency Management System in the Age of Big Data," Journal of Henan Polytechnic University (Social Sciences), vol. 17, no. 2, pp. 182-186, 2016.

[2] Huaxia warp weft network, "The 13th Five-Year plan for the construction of national emergency response system," http://www.gov.cn/zhengce/content/2017-07/19/content_5211752.htm, 2018-08-08.

[3] H. B. Zhang, X. Tong, "The Optimization of Chinese Public Emergency System: A Perspective of Public Policy," The Journal of Shanghai Administration Institute, vol. 13, no. 6, pp. 23-37, 2012.

[4] Z. Y. Dong, J. S. Song, "Thinking on the construction and perfection of China's emergency plan system," China Emergency Management, vol. 32, no. 11, pp. 17-21, 2014.

[5] Q. Q. Cao, "Research on decision mechanism of emergency management in large data environment," http://www.fx361.com/page/2017/0406/1436314.shtml, 2018-08-08.

[6] H. Z. Xun, D. Wang, "Constructing the logistic support system of China's Government Emergency Management," Chinese Public Administration, vol. 20, no. 1, pp. 21-24, 2004.

[7] B. Ma, Q. D. Mao, "The application of big data in emergency management," Chinese Public Administration, vol. 31, no. 3, pp. 136-141, 2015.

[8] P. Ye, D. Ding, X. Y. Zhang, "Research on big data driven tourism emergency management system," E-Government, vol. 14, no. 10, pp. 84-91, 2017. 